\title{
Attitudes of Nigerian Secondary School Chemistry Students Towards Concept Mapping Strategies in Learning the Mole Concept
}

Bamidele, E.F.

\author{
Adetunji, A.A.
}

Awodele, B. A.

Irinoye, J.

Department of Special Education and Curriculum Studies,

Faculty of Education, Obafemi Awolowo University, Ile-Ife

Doi:10.5901/ajis.2013.v2n2p475

\begin{abstract}
The study examined the effect of Concept mapping learning strategies on the learning outcomes of students in Chemistry. It compared the effectiveness of the use of different concept mapping strategies (hierarchical, flowchart and spider) used as advance organizers on students' performance and examined the attitudes of students towards the use of the concept mapping strategies in teaching the mole concept an important concept in Chemistry in the secondary schools. The study adopted the pretest-posttest-control group quasi experimental design. The population for the study comprised of Senior Secondary School class II (SSSII) students in Ife Central Local Government Area of Osun state, Nigeria. The Chemistry students in their intact classes in three randomly selected senior public secondary schools in the local government area were used for the study. A total of one hundred and thirty two (132) ssll chemistry students formed the sample for the study. The age range of the students was between 13 and 17years. The three schools were coeducational. The schools selected were randomly assigned to the treatment groups. Two research instruments were used for the study. These are; Problem Solving Achievement Test in Chemistry (PSATC) and Questionnaire on Attitude of Students towards Concept Mapping (QACSCM). The PSATC consists of 25-item multiple choice questions with five options constructed to serve as pretest to ascertain equivalence of ability of subjects and as posttest to determine the effect of the treatment on ability to solve numerical problems in chemistry based on the mole concept. The QACSCM consists of 10-item questionnaire, designed to find out the attitude of the students towards the use of concept mapping strategy in learning chemistry. The reliability coefficient of the PSATC was 0.92 while that of QACSCM was 0.66 . The two instruments were validated and reliability determined. The supplementary instructional package was the use of three types of concept maps (hierarchical, flowchart and spider) presented to the students as advance organizer. Results showed that there was no significant difference $F=1.19 ; p=0.24>0.05$ ) in the performances of the students exposed to either Hierarchical, Flowchart or Spider Concept Mapping strategies when used as advance organizers. This implies that using any of the concept mapping strategies as advance organizers produced a similar effect on the students' performance in their problem solving abilities. Result also indicated that there was no significant difference in the students' attitude to the concept mapping strategies. That is, those students that were taught with concept mapping strategies have similar attitudes to the strategies $(F=0.69 ; p=0.46)$. It is therefore concluded that the various types of concept maps used in this study were effective and students had similar attitude to the maps.
\end{abstract}

Key Words: Mole, Stoichiometry, Meaningful learning, Retention, Advance Organizers, Cognitive Structures, Concept Mapping, hierarchical, flowchart, spider concept maps.

\section{Introduction}

One of the broad aims of secondary education in Nigeria is the raising up of a generation of people who can think for themselves, respect the views and feelings of others, respect the dignity of labour, appreciate those values specified under Nigeria's broad national goals and live as good citizens. (Section 5,2.2g, N.P.E. 2004). The above national goals could be achieved only if chemistry is meaningfully taught in order to ensure continued interest of learners in the subject. Since the knowledge of chemistry is central to vocations in health services, pharmaceuticals, petroleum and petrochemical industries, agriculture, food processing, teaching services and extractive industries. Presently, in the secondary schools, many of the chemistry teachers adhere strictly to expository method of teaching. This may be partly 
due to their desire to cover the syllabus and partly to their attitude towards teaching due to economic situation in the country that does not encourage an average Nigerian teacher to try out new methods of teaching because of the perceived cost of the teaching materials. This has led to teachers not exposing the students to meaningful learning, and this at the same time has made students to perceive chemistry as abstract and a very difficult subject to understand.

In the long run, learners often resort to memorizing the concepts (i.e rote learning) without meaningful learning taking place. This could be the reason why students have been performing poorly in standard examinations such as the Senior School Certificate Examination (SSCE) conducted by West African Examination Council (WAEC), and the National Examination Council (NECO).

The above statement is attested to in the result of students in the West African Secondary School Certificate Examination (WASSCE) May/June, 2003 to 2010 as shown in Table 1.

Table 1. Trends of Performance in Chemistry in the West African Senior School Certificate Examination May/June 20032010

\begin{tabular}{|c|c|c|c|c|c|c|}
\hline \multirow[t]{2}{*}{ YEAR } & \multirow{2}{*}{$\begin{array}{l}\text { TOTAL } \\
\text { ENTRY }\end{array}$} & \multirow{2}{*}{$\begin{array}{l}\text { TOTAL } \\
\text { EXAMINED }\end{array}$} & \multirow{2}{*}{$\begin{array}{l}\text { TOTAL } \\
\text { ABSENT }\end{array}$} & \multicolumn{3}{|c|}{ NUMBER AND PERCENTAGE } \\
\hline & & & & $\begin{array}{l}\text { CREDIT } \\
1.6\end{array}$ & $\begin{array}{l}\text { PASS } \\
7 \& 8\end{array}$ & $\begin{array}{l}\text { FAlL } \\
9\end{array}$ \\
\hline 2003 & 412480 & $\begin{array}{l}405447 \\
(98.29 \%) \\
\end{array}$ & $\begin{array}{l}7033 \\
(1.70 \%)\end{array}$ & $\begin{array}{l}165513 \\
(40.82 \%) \\
\end{array}$ & $\begin{array}{l}92909 \\
(22.91 \%)\end{array}$ & $\begin{array}{l}84875 \\
(20.93 \%) \\
\end{array}$ \\
\hline 2004 & 340367 & $\begin{array}{l}333272 \\
(97.91 \%)\end{array}$ & $\begin{array}{l}7095 \\
(2.08 \%)\end{array}$ & $\begin{array}{l}124250 \\
(37.28 \%)\end{array}$ & $\begin{array}{l}84384 \\
(25.31 \%)\end{array}$ & $\begin{array}{l}111188 \\
(33.36 \%)\end{array}$ \\
\hline 2005 & 361575 & $\begin{array}{l}353656 \\
(97.80 \%)\end{array}$ & $\begin{array}{l}7919 \\
(2.19 \%)\end{array}$ & $\begin{array}{l}179156 \\
(50.65 \%)\end{array}$ & $\begin{array}{l}65804 \\
(18.63 \%)\end{array}$ & $\begin{array}{l}96537 \\
(27.28 \%)\end{array}$ \\
\hline 2006 & 393207 & $\begin{array}{l}383694 \\
(97.58 \%)\end{array}$ & $\begin{array}{l}9513 \\
(2.41 \%)\end{array}$ & $\begin{array}{l}173103 \\
(45.11 \%)\end{array}$ & $\begin{array}{l}87645 \\
(22.84 \%)\end{array}$ & $\begin{array}{l}116230 \\
(30.29 \%)\end{array}$ \\
\hline 2007 & 434460 & $\begin{array}{l}424741 \\
(97.76 \%)\end{array}$ & $\begin{array}{l}9719 \\
(2.23 \%)\end{array}$ & $\begin{array}{l}196081 \\
(46.16 \%) \\
\end{array}$ & $\begin{array}{l}105602 \\
(24.86 \%) \\
\end{array}$ & $\begin{array}{l}112637 \\
(26.51 \%) \\
\end{array}$ \\
\hline 2008 & 468291 & $\begin{array}{l}456993 \\
(97.58 \%)\end{array}$ & $\begin{array}{l}11298 \\
(2.41 \%)\end{array}$ & $\begin{array}{l}198621 \\
(43.46 \%)\end{array}$ & $\begin{array}{l}121139 \\
(26.50 \%)\end{array}$ & $\begin{array}{l}116892 \\
(25.57 \%)\end{array}$ \\
\hline 2009 & 478235 & $\begin{array}{l}468546 \\
(97.97 \%)\end{array}$ & $\begin{array}{l}9689 \\
(2.03 \% \\
\end{array}$ & $\begin{array}{l}204725 \\
(43.69 \%) \\
\end{array}$ & $\begin{array}{l}114697 \\
(23.41 \%) \\
\end{array}$ & $\begin{array}{l}110260 \\
(25.39 \%) \\
\end{array}$ \\
\hline 2010 & 568291 & $\begin{array}{l}565643 \\
(97.50 \%)\end{array}$ & $\begin{array}{l}11930 \\
(2.50 \%)\end{array}$ & $\begin{array}{l}236059 \\
(50.70 \%)\end{array}$ & $\begin{array}{l}109944 \\
(23.61 \%)\end{array}$ & $\begin{array}{l}98165 \\
(26.08 \%)\end{array}$ \\
\hline
\end{tabular}

Source: West African Examination Council, Nigeria

From the table it could be observed that except in 2005, students with grade A1 to C6 were below 50\%. This implies that very few numbers of students would be having the opportunity of securing admission into science related courses like medicine, agriculture, pharmacy, geology, physical sciences, science education and engineering in the higher institutions and these are the courses that can lead in vocations like health services, pharmaceuticals, petroleum and petrochemical industries, engineering, agriculture, food processing, teaching services, extractive industries, e.t.c. necessary for industrial, commercial and economic development of a nation.

The Chief Examiner's report for the West African Senior School Certificate Examination 2010-2012 pointed out the reasons for candidate's poor performance in Chemistry. Some of which are: inability of the students to tackle most of the numerical questions; poor expressions and the use of non-chemical terms; poor knowledge of IUPAC nomenclature especially organic compounds; and writing of formulae and correct balanced chemical equations.

The students were observed to be deficient in the use of the mole concept and its application to stoichiometry. Stoichiometry is an important concept in chemistry. It expresses the mole ratio between the reactants and the products of chemical reactions. It lies at the core of quantitative chemistry, whether in the form of gravimetric analysis or volumetric analysis. Due to the importance placed on stoichiometry in the WAEC or NECO examinations for the Senior Secondary School, questions on practical chemistry usually include those on stoichiometry. Also, questions involving stoichiometry are always present in the theory paper and mole concept is the basis for tackling such questions. 
Some variables have also been adduced for this poor performance in research studies. Etiubon (2007) identified teaching resources and its manipulative adaptations as a factor. Similarly, Ezeliora (1999) and Eniayeju (2005) also pointed out that the use of concrete materials facilitates better and proper understanding of chemistry concepts. Ivowi (1997), Salau (2003) and Njoku (2004) identified students' attitude towards learning as a factor. However, effective strategies designed to promote efficient and meaningful learning have been found to rely upon connecting prior knowledge to new concepts (Ausubel, 1968; Barnes - Clawson, 1975; Ausubel, Novak \& Hanesian, 1978; Okebukola and Jegede, 1988; Carol, 1998; Ferry, Hedberg and Harper, 1998). Research studies have indicated that Concept Mapping is an example of such strategies (Novak and Gowin 1984: Chang, Sung and Chen, 2002; Canas, Hill, Carff, Suri, Lott, Gomez, Eskridge, Arroyo, and Carvajal, 2004; Novak and Canas, 2006).

Concept maps are two or three-dimensional spatial or graphic displays that make use of labeled nodes to represent relationships between pairs of concepts. It has been suggested that the concept map structure parallels the human cognitive structure, as it shows how learners organize concepts (Fisher et al., 1990; Clarke, 1991; and Ferry et al, 1998). When concepts and linking words are carefully chosen, these maps have been found to be useful classroom tools for observing nuances of meaning, helping students organize their thinking, and summarizing subjects of study (Canas, Hill, Granados \& Perez, 2003). From an educational perspective, a growing body of research indicates that the use of concept maps could facilitate meaningful learning (Schmid and Telaro, 1990; Okebukola and Jegede, 1998; Nicoll, Francisco and Nakhleh, 2001; and Canas, Hill, Carft, Suri, Lott 2004) and performance support systems (Canas et al, 2003).

Concept maps have been found to enhance learning in the following manner: as a scaffold for understanding; for consolidation of educational experiences, to improve affective conditions for learning, as an aid or alternative to traditional writing, and as a mediating representation (Canas, et al, 2003). Concept mapping serves as a strategy to help learners organize their cognitive frameworks into more powerful integrated patterns (Kinchin, 2005).

\section{Theoretical Framework}

The theoretical framework for this study is based on the cognitive learning theory. Concept mapping is grounded in Ausubel's Assimilation Theory (Ausubel, 1968; Ausubel, Novak \& Hanesian, 1978). Assimilation theory posits that new knowledge can be learned most effectively by relating it to previously existing knowledge. Concept Maps may be viewed as a methodological tool of assimilation theory that displays fundamental elements of the theory such as subsumption, integrative reconciliation and progressive differentiation. Concept Maps allow for the representation of non-hierarchical relationships or cross-links, as well as other types of non-hierarchical arrangements.

Over the past decades, Ausubel (1963) has been concerned with the problem of how meaningful verbal learning and retention can be facilitated through the use of extrinsic organizing devices that modify the learner's cognitive structure. He stressed that if existing cognitive structure is clear, stable, and suitably organized, it facilitates the learning and retention of new subject matter. However, if it is unstable, ambiguous, disorganized, or chaotically organized, it inhibits learning and retention. In order to describe the importance of classification in learning and retention and the strategy for deliberately manipulating cognitive structure so as to enhance proactive facilitation and to minimize proactive interference, Ausubel (1963) coined the phrase "advance organizer" which involves the use of appropriately relevant and inclusive introductory materials that are maximally clear and stable. These organizers are normally introduced in advance of the learning material itself and are used to facilitate establishing a meaningful learning set. The advance organizers help the learner to recognize that elements of new learning materials can be meaningfully learned by relating them to specifically relevant aspects of existing cognitive structure. The rationale for using organizer is based primarily on the importance of having relevant and otherwise appropriate established ideas already available in cognitive structure to make logically meaningful new ideas potentially meaningful and to give them stable anchorage. The organizer functions to 'bridge the gap' between what the learners already knows and what he needs to know before he can meaningfully learn the task at hand. It is to provide ideational scaffolding for the stable incorporation and retention of the more detailed and differentiated material that follows. This is the basis of this research study. The concept maps were introduced in advance of the learning materials to facilitate the establishment of meaningful learning set.

The central propositions in Ausubel's cognitive assimilation (subsumption) theory (Ausubel, 1968; Ausubel et. Al., 1978) which is the basis for concept mapping, that:

(1) Concepts derive their meanings through their inter-connections with other concepts; and 
(2) Meaningful learning occurs when fresh knowledge is consciously anchored to relevant concepts in the cognitive structure of the learner.

According to Wandersee (1990), concept mapping relates directly to such theoretical principles as prior knowledge, subsumption, progressive differentiation, cognitive bridging and integrative reconciliation. This theory involves the learner linking new specialized concepts to more generalized, more inclusive concepts in the learner's existing structure of knowledge (schema). The result of subsumption is that the Schema of the learner becomes progressively more differentiated leading to assimilation of newer information. This theory, therefore, asserts that cognitive structure is hierarchically organized and more inclusive, broad concepts are super-ordinate to less inclusive and more specific concepts. Furthermore concepts in the learner's cognitive structure undergo progressive differentiation in which greater inclusiveness and specificity of concepts are discerned, resulting in recognition of more prepositional linkages with other related concepts (Canas et. al. 2003)

The objectives of this study are therefore to:

(i) compare the effectiveness of the use of the different concept mapping strategies as advance organizers on students' performance in Chemistry and

(ii) determine the attitudes of students towards the use of concept mapping strategy in teaching Chemistry in the secondary schools.

\section{Research Hypotheses}

The following hypotheses were tested at 0.05 level of significance:

1. There is no significant difference in the performance of chemistry students taught with hierarchical, flowchart or spider concept mapping strategies used as advance organizer; and

2. There is no significant difference in the attitude of students in the three groups (Hierarchical, flowchart and Spider) towards the use of concept mapping strategy in teaching chemistry.

\section{Methodology}

The pre-test, post-test non-equivalent experimental design was used for the study.

There were three experimental groups. The design for the study is as represented below:

$\begin{array}{lll}\mathrm{O}_{1} & \mathrm{X}_{1} & 0_{2} \\ \mathrm{O}_{3} & \mathrm{X}_{2} & 0_{4} \\ \mathrm{O}_{5} & \mathrm{X}_{3} & 0_{6}\end{array}$

Where $0_{1}, 0_{3}$, and $0_{5}$ represent the pretest in the three groups, while $X_{1}, X_{2}$, and $X_{3}$, represent treatment 1 (Spider concept mapping strategy), treatment 2 (Hierarchical concept mapping strategy), and treatment 3 (flowchart concept mapping strategy) respectively. Also, $0_{2}, 0_{4}$, and $0_{6}$, represent the post test for the three groups.

\subsection{Variables}

The variables examined in this study are:

1. Independent Variables: These are the learning strategies used in the study. They are

i. $\quad$ Spider concept mapping strategy (SCMS)

ii. Hierarchical concept mapping strategy (HCMS)

iii. $\quad$ Flowchart concept mapping strategy (FCMS)

2. Dependent variable: This is the Chemistry achievement test scores.

\subsection{Population and Sample}

The population for the study consisted of all Senior Secondary class two (ssII) Chemistry students in Ife Central Local Government Area of Osun state, Nigeria. The Chemistry students in their intact classes in three randomly selected senior public secondary schools in the local government area were used for the study. A total of one hundred and thirty two (132) ssll chemistry students formed the sample for the study. The age range of the students was between 13 and 17years. The three schools were coeducational. The schools selected were randomly assigned to the treatment groups. 


\section{Research Instruments}

This study made use of the following instruments:

1. Problem Solving Achievement Test in Chemistry (PSATC)

This consists of 25-item multiple choice questions with five options constructed to serve as pretest to ascertain equivalence of ability of subjects and as posttest to determine the effect of the treatment on ability to solve numerical problems in chemistry based on the mole concept.

2. Questionnaire on Attitude of Chemistry Students towards Concept Mapping. (QACSCM)

This consists of 10-item questionnaire designed to find out the attitude of the students towards the use of concept mapping strategy in learning chemistry. Subjects were required to respond to each of the QACSCM on a five-point Likerttype scale ranging from strongly agree to strongly disagree.

\subsection{Validation of Research Instruments}

The process of validation of each of the two instruments used in this study are described below:

\section{Problem Solving Achievement Test in Chemistry (PSATC)}

The PSATC contains 25 multiple choice items based on the mole concept. The complete test items were given to two experienced chemistry teachers in the secondary schools who are seasoned examiners of WAEC and NECO for comments on the validity and correctness of the questions and options. Based on the comments of the assessors a few questions were modified.

The instrument was then field-tested on a random sample of 25 students selected from Senior Secondary class two in a school quite different from the one used for the study. The result of the field test was used to calculate the difficulty indexes ( $p$ ) of the test items. Those items with $p$ value between 0.32 and 0.72 were selected. Based on this, fifteen test items were dropped from an initial forty items and the twenty five items used for the study were retained. The final set of twenty five questions made up the PSATC. The reliability of the instrument was also determined using Kuder Richardson formular 20 (K-R 20) and the reliability coefficient was found to be 0.92 .

\section{Questionaire on Attitude of Chemistry Students towards Concept Mapping (QACSCM)}

The main purpose of the questionnaire was to obtain disposition of subjects in the experimental groups about the concept mapping strategy. The researcher initially produced a draft of twelve items. The item was based on a five - point Likert Scale and the ordering of the scale ranged from Strongly Agree (SA), Agree (A), Undecided (U), Disagree (D) to Strongly Disagree (SD). The draft was given to two experts in measurement and evaluation to comment on the items in terms of relevance, sentence structure and adequacy of the instrument. Based on their recommendations, two of the items were dropped.

Subjects were required to respond to each of the QACSCM items. The responses were scored $+2,+1,0,-1,-2$ for positive items and $-2,-1,0,+1,+2$ for negative items. The reliability of the questionnaire was determined by using Pearson Product Moment correlation formula and then Spearman Brown formula (Split-half method) for correction. The reliability coefficient was calculated to be 0.66 .

\section{Concept Mapping Instructional Material (CMIM):}

These were designed and prepared by the researcher to teach the subjects on the mole concept and the related topics. The CMIMs were in three different categories; the spider, the hierarchical and the flowchart types. These were used for teaching the experimental groups.

\section{Data Collection}

The researcher visited the schools and contacted the appropriate authorities (that is, the school principal and head of science department) and chemistry teachers in the schools especially SSII chemistry teachers for their assistance during 
the first week of the study. With the assistance of the chemistry teachers the sampled students were given the pre-test to ascertain uniformity of their entry level during the first week of the experiment.

The schools were randomly assigned to the different concept-mapping strategies. The first group was assigned spider concept mapping strategy, while the second and third groups were assigned hierarchical and the flowchart concept mapping strategies respectively.

Treatment commenced the following week after the administration of pre-test. In the experimental group, the researcher first explained why concept mapping is a tool for learning and how it can be used to show relationships among various concepts. The students were then taught using teacher-constructed concept maps. The maps were presented to the students in advance of the normal teaching to make them to see the relationships between the various concepts involving the mole. The treatment lasted for five weeks of two periods per week. Topics taught in each group covered the mole concept, chemical equations and stoichiometry, gas laws and calculations involving gas volumes, solubility and electrolysis. After the treatments, subjects were post-tested to determine their level of attainment/achievement in the topics covered and to find out the effect of the teaching strategies. Also, the questionnaire on the students' attitude towards the concept mapping was administered after the post-test. All the scripts of the students involved in the study were marked by the researcher and the records kept for the purpose of data analysis.

\section{Data Analysis}

The data collected were analyzed using One Way Analysis of Variance (ANOVA). In order to determine possible differences in the background knowledge of the subjects, the chemistry achievement test (pre-test) for the four groups was subjected to ANOVA test. The same was also done on the Post-test scores. Significant difference in the students' attitude towards the concept mapping strategies was ascertained by using ANOVA also. The F-tests were measured at $p$ $<0.05$ level of significance.

\section{Results}

The results of this study are presented based on the hypotheses generated in chapter one. However, in order to determine possible differences in the background knowledge of the students in their problem solving ability in chemistry using the mole concept, the Problem Solving Achievement Test in Chemistry (PSATC) was first administered as pre-test. The data obtained was subjected to One-Way Analysis of Variance (ANOVA) and the F value was calculated. The result is presented in Table 2 below.

Table 2. Analysis of Variance of Scores of the Four Groups on the Pre-test Scores

\begin{tabular}{|l|l|l|l|l|l|}
\hline Sources of variation & Sum of Squares & df & Mean Square & F & Sig. \\
\hline Between Groups & 766.119 & 2 & 383.060 & & \\
Within Groups & 24744.094 & 129 & 191.815 & 1.997 & 0.117 \\
Total & 25510.213 & 131 & & & \\
\hline
\end{tabular}

From the table, the result of the pre-test is not significant as $p=0.117$. This indicated that there was no significant difference in the background knowledge of the three groups with regards to their problem solving ability in chemistry based on the mole concept as shown by their performance in the pre-test. This implies that all the students had similar background knowledge.

\section{Hypothesis 1}

There is no significant difference in the performance of chemistry students taught with the different concept mapping strategies (Spider, Hierarchical and Flowchart) when used as advance organizer.

The essence of this hypothesis is to find out the relative effectiveness of the three concept mapping strategies as advance organizers in learning chemistry concepts based on the mole. The concept maps were presented to the 
treatment groups at the commencement of the teaching. This serves as advance organizers. In order to test this hypothesis, the post test scores of the students in the experimental groups were subjected to Analysis of Variance (ANOVA). The results of the analysis are presented in Table 3

Table 3. Analysis of Variance (ANOVA) on the Performance of Treatment Groups that used the Concept Maps

\begin{tabular}{|l|l|l|l|l|l|}
\hline Source & Sum of Squares & df & Mean Square & F & Sig. \\
\hline Between & 556.533 & 2 & 278.267 & & \\
Groups & 30411.519 & 130 & 233.935 & 1.190 & 0.236 \\
Within Groups & 30968.052 & 132 & & & \\
Total & & & & \\
\hline
\end{tabular}

The results presented in Table 3 shows that there was no significant difference $(p=0.236)$ in the performances of the students exposed to either Hierarchical, Flowchart or Spider Concept Mapping strategies when used as advance organizers. $F_{c}=1.190, p>0.05$. This implies that using any of the concept mapping strategies as advance organizers produced a similar effect on the students' performance in their problem solving abilities. Thus the null hypothesis was accepted.

\section{Hypothesis 2}

There is no significant difference in the attitude of students in the three groups that used the concept mapping strategies towards the use of concept mapping strategy in teaching chemistry. In order to test this hypothesis, a questionnaire tagged "Questionnaire on Attitude of Chemistry Students towards Concept Mapping (QACSCM)" was administered to the subjects after the treatment. Subjects were required to respond to each of the questionnaire items on a five-point Likerttype scale ranging from strongly agree to strongly disagree.

In order to determine whether there was any significant difference in the students' attitude to the CMS in the three treatment groups, the scores of the respondents on the attitude questionnaire was subjected to Analysis of Variance and the result is as presented in Table 4

Table 4. Analysis of Variance on Chemistry Students' Attitude towards the use of Concept Mapping

\begin{tabular}{|l|l|l|l|l|l|}
\hline & & & & & \\
& Sum of Squares & Df & Mean Square & F & Sig. \\
\hline Between Groups & 105.864 & 2 & 52.932 & .691 & .459 \\
Within Groups & 9805.136 & 128 & 76.603 & & \\
Total & 9911.000 & 130 & & & \\
\hline
\end{tabular}

Results showed that there was no significant difference in the students' attitude to the concept mapping strategies. That is, those students taught with concept mapping strategies have similar attitudes to the strategies $F_{c}=0.691 ; p>0.05$. Therefore, the hypothesis was accepted.

\section{Discussion}

The results of the study indicated that there was no significant difference in the performances of the students exposed to either hierarchical, flowchart or spider concept mapping strategies when used as advance organizers. This implies that using any of the concept mapping strategies as advance organizers produced a similar effect on students' performance in their problem-solving abilities in Chemistry. This is in agreement with Ausubel's (1968) claims, that by presenting a global representation of the knowledge to be learned, advance organizers foster "integrative reconciliation" of the sub-domains 
of knowledge - the ability to understand interconnections among the basic concepts in the domain. Various research studies have utilized concept maps as an advance organizer (Novak \& Gowin, 1984; Novak, 1998; Willerman \& Macharg, 1991, Cffey and Canas, 2003, Novak and Canas 2008). They maintained that concept maps advance organizers help learners to recognize that elements of new learning materials can be meaningfully learned by relating them to specifically relevant aspects of exiting cognitive structure. The organizer bridges the gap between what the learner already knows and what he needs to know before he or she can meaningfully learn the task at hand.

Research studies by Arguea \& Canas (1998) developed a set of concept maps used as advance organizers in a class on quantitative methods in business. The concept maps detailed the use of applied statistics at the graduate level. The map contains basic concepts of the course. The students found the concept map very useful and enhance their academic performance in the course. There is also an indication that learning effects are enhanced in the course of concept mapping. Learners adopt an active, deep and questioning approach to the subject matter, such active, selfengaging, transformational interaction with learning materials has been suggested to enhance learning in general (Canas et al., 2003). Thus, Novak (1984) and Kothe (2009) reiterated that amidst all of the research that has been done in the field of education, concept mapping has emerged as the latest success in a series of new teaching strategies which is now being upheld. Thus, the idea of presenting and summarizing concepts/topics in a subject by using concept map is advocated for teachers of chemistry since it is found to be effective for learning.

On the attitude of the students towards the use of concept maps it was found that the students have a positive attitude to concept mapping strategy. Most of the students (97\%) agreed that concept mapping is good for learning chemistry and that the maps enabled them to see the relationship between the various chemistry topics involving the mole. That is, almost all students expressed the view that the concept mapping strategy was really helpful for learning chemistry and understanding the structure and inter-relationship of the chemistry content. In terms of affective acceptance, the group had a positive attitude for using the concept mapping strategy. The overwhelming majority of the students were of the opinion that concept mapping can be a feasible chemistry instructional strategy. Most of the students liked, and felt satisfied with the adoption of concept mapping as a supportive learning strategy. These opinions are consistent with the studies by some scholars (Chang et al., 2002; Freeman \& Jessup, 2004; Chiou, 2008).

\section{Conclusion}

The study concludes that the concept mapping strategy enhanced students' performance and any of the strategies or concept maps can be used to support teaching in the classroom. This is because the maps clearly defined a central idea and allows one to figure out the links among the key ideas more easily and also to see all the basic information at a glance. As a result it makes recall and review more efficient.

Again, almost all students expressed the view that the concept mapping strategy was really helpful for learning chemistry and understanding the structure and inter-relationship of chemistry concepts. Most of the students liked, and felt satisfied with, adopting concept mapping as an aid to learning. The opinions of students support the merit of concept mapping in the integration of knowledge. Therefore, Concept maps can be effective for affective, as well as cognitive, instructional objectives.

\section{References}

Arguea, N. \& Canas, A.J. (1998). Concept Maps as a Tool for Distance Learning in Applied Statistics Courses. (in Canas and coffey et al. 2003 Ed.). The Institute for Human and Machine Cognition, Pensacola. www.ihmc.us

Ausubel, D.P. (1963). The Psychology of Meaningful Verbal Learning. New York. Grine \& Stratton.

Ausubel, D.P. (1968). Educational Psychology: A Cognitive View. New York. Holt, Rinehart and Winston Inc.

Ausubel, D.P., Novak, J.D. \& Hanesian, H. (1978). Educational Psychology: A Cognitive view. (2nd ed.). New York. Holt, Rinehart and Winston.

Barnes-Clawson, E.U. (1975). Do Advance Organizers Facilitate Learning? Review of Education Research, 45(4), 637-659.

Canas, A.J., Coffey, J.W., Carnot, M. J., Feltovich, P., Hoffman, R.R., Feltovich, J. and Novak, J. D. (2003). A Summary of Literature Pertaining to the Use of Concept Mapping Techniques and Technologies for Education and Performance Support. The Institute for Human and Machine Cognition. Pensacola, Florida. www.ihmc.us

Canas, A.J., Hill, A., Granados, J.D., Perez, C. C. (2003). The Network Architecture of Cmaps Tools. Technical Report ihmc Cmap Tools, 93. 
Carol, M.S. (1998). What Instructional Designs need to know about Advance Organizers. International Journal of Instructional Media, 25(3), 253.

Chang, K., sung, Y. \& Chen I. (2002). The Effect of Concept Mapping to Enhance Text Comprehension and Summarization. Journal of Experimental Education, 7(1), 5-23.

Chiou, C-C (2008). The effect of concept mapping on students' learning achievements and interest. Innovation in Education and Teaching International Vol. 45. No. 4. 375-387.

Clarke, J.H. (1991). Using Visual Organizers to Focus on Thinking. Journal of Reading. 34(7), 526-534

Coffey, J.W. and Canas, A. J. (2001). An Advance Organizer Approach to Distance Learning Course Presentation. http://www.icte-org

Eniayeju, P.A. (2005). Enhancing Professional STM Teachers' Role in Lifelong Education: The function of Instructional Support Practices. STAN Annual Conference.

Esiobu, A.W. and Soyibo, K. (1995). Effects of Concept and Vee Mapping Under Three Learning Modes on Students' Cognitive Achievement in Ecology and Genetics. Journal of Research in Science Teaching, 32(9), 971-995.

Ezeliora, B. (1999). A Comparative Analysis of the Effect of Improvised and Standard Models and Graphics on Students' Achievement and Interest in Chemistry. Journal of the Science Teachers Association of Nigeria 34, 1-5.

Federal Government of Nigeria (2004). National Policy on Education. Lagos.

Ferry, B., Hedberg, J. and Harper, B. (1998). How do Preservice Teachers Use Concept Maps to Organize their Curriculum Content knowledge? Journal of Interactive Learning Research 9(1). 83-84.

Freeman, L.A., \& Jessup, L.M. (2004). The power and benefits of concept mapping: Measuring use, usefulness, ease of use, and satisfaction. International Journal of Science Education, 26(2), 151-169.

Ivowi, U.M.O. (1997). Redesigning School Curricular in Nigeria, WCCI Region Seminar, NERDC Conference Center, Lagos.

Kinchin, I.M. (2005). Writing to be Published or Writing to be Read. Journal of Natural History, 39, 3229-3233.

Koleoso, A. (1990). Applications of Mole Concept. Ibadan, Tabnimo publishing co.

Kothe Denise (2009). Meaningful Learning: A Collaborative Literature Review of Concept Mapping. http://www.m/rg.org/clrconceptmapping.html

Novak, J. D. and Canas, A. J. (2008). The Theory Underlying Concept Maps and How to Construct and Use them. Technical Report IHMC Cmap Tools. Institute for Human and Machine Cognition. http://cmap.ihmc.us/publications/ResearchPapers TheoryUnderlyingConceptMaps.pdf

Novak, J.D. \& Gowin, D.B. (1984). Learning How to Learn. New York. Cambridge University Press.

Nicoll, G, Francisco, J. and Nakhleh, M.B. (2001). An Investigation of the Value of Using Concept Maps in General Chemistry. Journal of Chemical Education, 78(8), 1111-1117.

Njoku, Z. C. (2004). Fostering the Application of Science Education Research Findings Nigerian Classrooms. Strategies and Need for Teachers' Professional Development. STAN 2005, 45th Annual Proceedings. Pp 217-222

Okebukola, P.A. and Jegede, O. (1998). Cognitive Preferences and Learning Model as Determinants of Meaningful Learning through Concept mapping and Achievement in Secondary School Physics. Journal of Research in Science Teaching, 23(4), 315-333.

Salau, M.O. (2003). Constraint against life coping skills in the implementation of the National policy on Education at the Secondary School Level and Strategies for Redress. Journal of CON, 10(2), 465-470.

Schmid, R.F. and Telaro, G. (1990). Concept Mapping as an Instructional Strategy for High School Biology. Journal of Educational Research, 84(2), 78-85.

Wandersee, J.A. (1990). Concept Mapping and the Cartography of Cognition. Journal of Research in Science Teaching, 27(10), 923936.

White, R. and Gunstone, R. (1992). Probing Understanding. New York. Falmer Press.

Willerman, M. and MacHarg, R.A. (1991). The Concept Map as an Advance Organizer. Journal of Research in Science Teaching, 28(*), 705-711.

\section{Appendix I}

\section{Chemistry students' attitude towards the use of concept mapping and chemistry Instructions}

Please complete this questionnaire with all honesty. Read each statement and indicate your response by putting a tick $\sqrt{ }$ inside one of the columns below.

\section{Section A: Respondent's Biodata}

School

Gender: Male

Female 


\section{Section B:}

Please tick your response to each statement using the key below

SA - Strongly Agree

A - Agree

$U$ - Undecided

D - Disagree

SD - Strongly Disagree.

\begin{tabular}{|l|l|l|l|l|l|l|}
\hline No & Statements & SA & A & U & D & SD \\
\hline 1 & The concept mapping is good for learning chemistry & & & & & \\
\hline 2 & $\begin{array}{l}\text { Concept maps enable me to see the relationship between } \\
\text { the various chemistry topics involving mole }\end{array}$ & & & & \\
\hline 3 & I have seen such maps before & & & & & \\
\hline 4 & This is my first time of seeing it in Chemistry & & & & \\
\hline 5 & $\begin{array}{l}\text { The concept map does not enable me to understand how to } \\
\text { solve numerical problems in chemistry. }\end{array}$ & & & & \\
\hline 6 & $\begin{array}{l}\text { I find concept mapping method for learning chemistry easy } \\
\text { to comprehend }\end{array}$ & & & & \\
\hline 7 & $\begin{array}{l}\text { Concept mapping helps me to better understand the } \\
\text { chemistry topics in relation to the Mole }\end{array}$ & & & & & \\
\hline 8 & $\begin{array}{l}\text { I did not enjoy learning chemistry by using concept } \\
\text { mapping strategy }\end{array}$ & & & & & \\
\hline 9 & The Concept map is too complex to understand. & & & & & \\
\hline 10 & $\begin{array}{l}\text { I would like to develop my own concept map in other } \\
\text { Chemistry topics. }\end{array}$ & & & & \\
\hline
\end{tabular}

